\title{
Is Empathy Necessary for the Practice of "Good" Medicine
}

\author{
Hanni K. Bouma*
}

Memorial University of Newfoundland Medical School, St. John's, Newfoundland, Canada

\begin{abstract}
Medicine is explicitly committed to the traditional values of empathy, compassion, and altruism. Along with the "middle" principles of beneficence, non-maleficence, justice and respect for autonomy, these are among the values which form the ethical framework by which physician conduct is evaluated. But how is empathy to be understood as fundamental to the practice of ethical medicine? Should it be construed as a moral obligation? In this paper, I argue that empathy in the treatment of patients should not be upheld as a moral requirement for the practice of "good" medicine: such a construal of the role of empathy in professionalism cannot be supported by the substantive theories of utilitarianism, deontology, feminist ethics, or virtue ethics. Moreover, empirical research into the nature of empathy shows it to be a trait that varies substantially between individuals and that variation is governed to a notable degree by factors beyond the individual's control.
\end{abstract}

\section{INTRODUCTION}

It is evident that not all physicians are empathic caregivers. Indeed, the proportion of physicians who are genuinely empathic towards patients appears to be declining. As just one indicator of this, a 1992 Gallup Poll found that 56\% of those interviewed agreed with the statement, "Doctors don't care about people as much as they used to" (American Medical Association, 1992). For decades now, the "hidden" curriculum of medical education has been condemned for producing uncaring and amoral physicians (Hafferty \& Franks, 1994). More recently, this condemnation reached a climax when objective studies confirmed that empathy amongst medical students and residents declines as they progress throughout their training (Newton et al., 2000; Spencer, 2004; Hojat et al., 2004). By consequence, an extensive literature has emerged on the questions of how physicians should be empathic (Halpern, 2003; Benbassat \& Baumal, 2004; Larson \& Yao, 2007), how it should be measured (Hojat et al., 2004; Stepien \& Baernstein, 2006), and how best to "educate" empathic physicians (Shapiro et al., 2004; Platt \& Keller, 1994; Burack et al., 1999; Winefield \& Chur-Hansen, 2000). Evidently, empathy in medicine is very much on the radar today.

It seems clear from these papers that physicians today are expected to demonstrate empathy, compassion and altruism in their treatment of patients. Indeed, this expectation is explicitly written into the codes of ethics of many professional associations, which routinely cite these as values fundamental to medical ethics (i.e. Canadian Medical Association Code of Ethics, 2004). Patients expect their physicians to be understanding and to respect their autonomy, and this is expressed in part through empathy. But how is empathy to be understood as a professional value? Is it a necessary part of "good" (as in "ethical") physician conduct, or is it simply good (as in "advantageous") to be empathic towards patients? These questions have thus far been neglected in discussions of physician empathy. My goal in the first part of this paper is to clarify the role of empathy in medical ethics.

*Address correspondence to this author at the 25A Cornwall Crescent, St. John's, Newfoundland, Canada, A1E 1Z4;

E-mail: hannibouma@hotmail.com
Another question that has been under-explored is why so few physicians are empathic when most, if not all, physicians admit the value of empathy in the treatment of patients? To illustrate, one study asked 214 physicians to rank the qualities and behaviour of a "good" doctor, and found that "a humane relation to patients" was rated more highly than all other traits and abilities, including "medical knowledge and skills" and "research ability." Nevertheless, of the above 214 physicians (all from the same hospital), only 40 (19\%) were identified by their fellow colleagues as "compassionate-empathic physicians" (Carmel \& Glick, 1996, p. 1258). Surely the desire and motivation to be empathic is present in many of the 174 others. What, then, is holding them back? Many explanations have been proposed elsewhere, concentrating mainly on work conditions, changes in health care delivery, medical training, and the influence of rational positivism. One explanation has not been adequately addressed, though: the presence of natural constraints on an individual's empathic capacities. In the last sections of this paper, I argue that evidence from behavioural genetics, psychology and neuroscience reveals a significant role for nature in determining individual differences in empathy. Obviously, the greater the influence of nature on individual empathic capacities, the lesser the degree to which an individual can choose to be empathic. This has implications for the central question of this paper: should empathy be understood as necessary for the practice of "good" medicine?

\section{WHAT IS EMPATHY?}

A substantial literature exists on the nature of empathy per se. At times, it is conceptually identified with and at times contrasted to compassion (Carmel \& Glick, 1996), caring (Stockdale \& Warelow, 2000; Allmark, 1998), sympathy (Wispé, 1986; Gruen \& Mendelsohn, 1986) and concern (Fox \& Lief, 1963; Halpern, 2003). And as noted above, much has also been written about the nature and importance of empathy in the clinical practice of medicine. The empathy of the medical professional is usually characterized as having an affective component (the capacity to "imagine" [Stepien \& Baernstein, 2006, p. 524] and "enter into" [Hojat et al., 2002b, p. 1563] the experience and feelings of the patient); a cognitive component (an intellectual ability to understand the patient's perspective and to view the world from that per- 
spective); and a behavioural component (the ability to "convey understanding of those emotions and perspectives back to the patient" [Stepien \& Baernstein, 2006, p. 524]). Some conceptualize these components as evolving from a "multiple-phase process": first one gains insight into the patient's perspective, then one becomes engaged with the patient which elicits a feeling of compassion that moves one to act in a helping manner (Benbassat \& Baumal, 2004). Others conceptualize empathy as more akin to events or psychological dispositions, and argue that one or more of the three components is necessary for physician empathy, while the others are undesirable and/or unnecessary.

The prevailing view in the medical literature of the 20th century was that professional empathy, unlike sympathy, is a purely intellectual form of knowing about the emotional state and perspective of the patient. The physician shares his understanding with the patient, but none of his emotions. This view, otherwise characterized as "detached concern" (Fox \& Lief, 1963), "neutral empathy" (Blumgart, 1964), or "compassionate detachment" (Hojat, 2002b, p. 1563) was defended by Sir William Osler (1912) as essential to avoiding over-identification with patients, compromising both the physician's "clinical neutrality" and "personal durability" (Hojat, 2002b, p. 1563). Instead of experiencing the patient's suffering alongside them, the physician should "see into" and "study" the patient's "inner life" from an objective standpoint (Osler, 1963, p. 29). According to defendants of this view, the cognitive form of empathy depends centrally on two capacities: 1) the ability to "identify and understand" patients' emotions and concerns without actually experiencing them; and 2) the ability to view the world from their perspective (Stepien \& Baernstein, 2006, p. 524).

This conception of empathy as "detached concern" has been convincingly attacked as inadequate by scholars such as Halpern (2003), who argues that this ideal is both hard to achieve in practice and difficult to accept as a genuine form of empathy. "True" empathy, as understood outside the context of medicine, involves being "moved by another's experiences" (Halpern, 2003, p. 670). The idea that the physician does not need affective understanding of the patient to have empathy arises from the "overarching norm of detachment" within medicine. This view conflicts with our natural way of relating to people, though: we resonate with the emotions of other people not as a "special professional skill" but rather as part of "ordinary communication" (Halpern, 2003, p. 671). Physicians may "strive to view patients' emotions objectively" but "cannot genuinely overcome all emotions" - nor should they, in her view. Physicians should instead use their involuntary "emotional resonance" with patients in the service of the cognitive goal of understanding patients' emotions (Halpern, 2003, p. 670). After all, merely "knowing that" the patient experiences a particular emotion is not the same as "knowing how" the patient feels, and the attempt to avoid all emotional engagement invariably leaves both the physician and the patient unsatisfied with the clinical encounter. Halpern's cognitive-emotive conception of empathy therefore requires less of the physician by way of emotional selfcontrol, but does suggest that, in order to experience "true" empathy, the physician must share some of the patient's emotions and be "moved" by the patient's suffering.
A third view emphasizing the behavioural component of empathy has recently come to prominence. Larson and Yao (2005) propose an "emotional labor" model of empathy, whereby physicians engage in either "deep acting" or "surface acting." The former is analogous to "method acting" amongst stage and screen actors, whereby the physician has genuine emotive and cognitive understanding of the patient and acts in accordance with this shared knowledge and feeling. This differs markedly from surface acting, whereby the physician deliberately displays emotions consistent with empathy in the absence of genuine emotional and cognitive empathy for the patient (Larson \& Yao, 2005, p. 1100). Because reliance on surface acting leads to lower job satisfaction (Brotheridge \& Lee, 2002) and, over the long-term, may result in physician burnout and cynicism, deep acting is the preferred form of empathy advocated by the authors. Nevertheless, both forms of acting are characterized as "skills" or "techniques" ("empathic processes") that require "effort, dedication, and patience" to learn (Larson \& Yao, 2005, p. 1105). Thus, unlike the purely cognitive and cognitiveemotive accounts above, this account allows for a form of empathy (surface acting) that is purely behavioural, devoid of both cognitive and emotive domains of understanding.

In the end, it seems that a genuine form of physician empathy requires four dimensions working in concert - cognitive, emotive, behavioural and moral. This last component is not explicitly mentioned in the above accounts but is, it seems, assumed implicitly within them: the moral dimension involves the physician being internally motivated to empathize with the patient. That is, empathy motivated by extrinsic factors (ie. the likeability of the patient, monetary reward or the desire for a "good grade") is not genuine. The physician must have a desire to empathize because they perceive it to be a "good" thing to do. Consider, then, the following example demonstrating why the other dimensions are also needed for physician empathy to be genuine and effective:

[A] physician could cognitively perceive a patient's empathy and communicate this by saying, "I see you are anxious," yet have the statement fall flat. But if the physician adds the desire to empathize, and becomes emotionally engaged by imagining what the patient's anxiety must feel like, his facial expression and tone of voice are more likely to make the patient feel understood, not merely labelled. In turn, the patient's sense of being truly understood is likely to encourage further disclosure and foster trust (Stepien \& Baernstein, 2006, p. 524, italics added).

Hence, I am inclined to agree with Halpern (2003) that physician empathy ought to include the emotional attunement to and sharing of the patient's emotions in addition to the cognitive capacities of perspective-taking and understanding. After all, one cannot succeed in understanding the patient's emotions and concerns from a purely cognitive standpoint without effectively eliciting the patient's concerns and emotions during the interview process. Thus, the "purely cognitive" account of empathy is too limited; the physician needs to use his "emotive attunement" capacities to help guide him "about when to ask questions, when to stay silent, and when to repeat important words" (Halpern, 2003, p. 673). And as Halpern notes, studies show that "patients 
sense whether physicians are emotionally attuned," and trust those "who respond to their anxiety with their own responsive worry" (2003, p. 673). Further, in Larson \& Yao's "purely behavioural" conception of empathy, the surface acting option is felt to be undesirable in the long run precisely because it involves no emotive or cognitive dimensions of empathy. This entails risks to the physician's longterm well-being and would likely be ineffective in engendering patient trust. Thus, the kind of physician empathy that I will discuss in this paper assumes a cognitive, an emotive, a behavioural and a moral dimension - these are, I think, the components of genuine empathy.

\section{WHAT'S GOOD ABOUT EMPATHY?}

These attempts to determine what physician empathy should be are motivated by the shared knowledge that empathy is a value fundamental to medical professionalism. But what is good about empathy? And is it so valuable that it should be required of physicians in order to be ethical?

That there are benefits to being an empathic physician is indisputable; physician empathy has been associated with reduced malpractice litigation (Levinson, 1994); better treatment adherence (Roter et al., 1997b); fewer physician burnouts (Roter et al., 1997a); decreased patient anxiety (Butow et al., 1997; Rietveld \& Prins, 1998); physician satisfaction (Suchman et al., 1993, Hojat et al., 2002b); improved patient recovery (Halpern, 2001); patient satisfaction (Levinson, 1994); good clinical relationships (Nightingale et al., 1991); dutifulness (Wolf, 1980); good attitudes toward elderly patients (Bagshaw \& Adams, 1986); and the list goes on. Others have noted some undesirable consequences of physician empathy: it can decrease the success rate of procedures and lead to dependency, inefficiency, burnout (Curzer, 1993), and emotional exhaustion (Carmel \& Glick, 1996, p. 1259) (though this clearly conflicts with statements made by others in the literature [Roter et al., 1997a; Thomas et al., 2007]). Empathic physicians may even be more likely to commit suicide: psychiatrists score the highest on empathy measures of all physicians but also have particularly high suicide rates, leading some to speculate that there may be a causal connection between the two (Restak, 2006, p. 103). Most commentators seem to agree (with a few exceptions [Curzer, 1993; Van Hooft, 1987]), however, that the benefits of empathy outweigh the costs.

There are plenty of reasons to see empathy as a good thing for physicians to manifest. But these are not reasons to see it as a requirement for being a "good" (as in "ethical") physician. The medical profession did not begin espousing empathy as a fundamental value once the studies demonstrating its favourable consequences began rolling in. If there were no demonstrated benefits to being empathic towards patients, the profession would no doubt still value it. Hence, empathy is not understood as "good" because of a favourable cost/benefit ratio (a utilitarian standpoint), nor are physicians enticed towards being empathy by virtue of its beneficial consequences. Rather, empathy is a value intrinsic to professionalism, as well as being instrumentally valuable as a means to avoid malpractice litigation, increase treatment adherence amongst patients, or decrease patient anxiety (or any other of the previously listed benefits). The former makes empathy "good" while the latter makes it simply good. But is empathy "good" per se or is its "goodness" contingent upon something else? Our intuitions tell us that all empathy is not "good": for instance, becoming too empathically engaged with a patient threatens not only the emotional health of the physician (and possibly the patient) but also his clinical judgement and neutrality. There seem to be right ways and wrong ways to be empathic towards patients. Hence, empathy is "good" only if it does not compromise the physician's ability to be ethical in other ways.

But what justifies the characterization of empathy as "good" at all? And if it's to be seen as "good," does that mean that all physicians, insofar as they are ethical, must be empathic? This would be a strong claim on the part of medical professionalism, and one that warrants ethical analysis. The best-suited theories for justifying an "ethic of empathy" are feminist ethics and virtue ethics. Deontology is less reasonable than these others because empathy cannot feasibly be made a moral principle (alongside justice, benificence, non-maleficence and the respect for autonomy) (Beauchamp \& Childress, 1994). In part, this is because moral principles entail duties and responsibilities on the part of physicians that must be exercised universally and equally with respect to all patients. It seems hardly reasonable to make empathy a duty for all physicians, to be manifest in the same way for all patients regardless of their individual abilities, the clinical circumstances, or characteristics of the patient and their illness (Stockdale \& Warelow, 2000, p. 1259). Furthermore, choice and autonomy are paramount values in deontological ethics, and reason (devoid of feeling) is supposed to guide moral decision-making and conduct. As we will see in the next section, morally obligatory empathy, like morally obligatory caring, is largely antithetical to the values and principles of traditional (Kantian) deontology.

\section{Should Empathy be Required of Physicians as Part of an "Ethic of Caring"?}

Perhaps empathy is "good" because caring is the major component of physician morality? As noted earlier, caring and empathy are certainly related but not identical. The latter specifically involves being internally motivated to empathize; understanding another person's experience, feelings and concerns; sharing in that experience with them; seeing the world from their perspective; and conveying this understanding through appropriate behaviours. They are alike in both having an affective component, and the moral component of empathy (the internal motivation to empathize) may indeed depend on having caring feelings towards the other person. Hence, one can care about someone without empathizing with them but not likely empathize without caring about them in some way.

An ethic of caring, then, may indeed be an appropriate framework for defining ethical conduct as necessarily empathic. This substantive ethical theory emerged as a critique of rational, justice-oriented ethics (i.e. Kantian ethics or Rawls" "justice as fairness" theory) by feminist ethicists, and was founded upon a feminist perspective of moral development that opposed the prevailing view developed by Lawrence Kohlberg. Carol Gilligan's psychology research led her to characterize three stages in women's moral development, progressively leading from interest in the self, toward interest in the other, toward interest in the self connected to 
the other. Thus, the highest stage of moral development, on Gilligan's reading, is a relational one (Gilligan, 1982). This contrasts with Kohlberg's six stages of moral development, which Gilligan regarded as "male-oriented." In Kohlberg's theory, the highest stage involves abstract reasoning using universal ethical principles (ie. Kant's Categorical Imperative). Relational modes of moral reasoning are more consistent with what Kohlberg calls "conventional" reasoning (stages three and four) (Crain, 1985). In stage three, characteristic of adolescents, the self is concerned with filling social roles: it is believed that there is inherent value in trying to live up to social expectations that one be a "good boy" or a "good girl." In this stage, the morality of one's actions is evaluated in terms of their consequences for one's relationships. Thus, in Kohlberg's theory, the "male" whose moral reasoning is similar to that of the most developed "female" is actually quite immature in his moral development. Interestingly, medicine, insofar as its conception of ethical conduct within the patient-physician relationship is concerned, has in some ways shifted its attention away from the Kohlbergian view of moral reasoning - which is motivated by concern for principles, laws, justice - towards a more feminine view of moral reasoning motivated by concern for others. That is, in terms of the explicit values championed in medicine and medical education, it seems that less emphasis is now placed on the strictly cognitive aspects of the patient-physician relationship and more value is attached to the affective elements of that relationship - caring, compassion and empathy. Does this mean that medicine should ground these values in a "feminine" theory of ethics?

Gilligan and Nel Noddings, the key proponents of an "ethic of caring," defended their "feminine" approach to morality as emphasizing "interdependence" and "the maintenance of relationships," whereby "attachment and detachment" are the central moral concerns. The "ideal" ethic of care is committed to an ontological conception of the self as inherently social ("the more connected the self is to others, the better that self is" [Tong, 2002]) and it conceives, epistemically, of truth as tied centrally to its particularity, concreteness, partiality, and emotionality (Clement, 1996, pp. 35). Justice-oriented theories, by contrast, take autonomy to be a fundamental value, and conceive of the self as individualistic and independent; they give priority to equality over relationships and conceive of universal, abstract, impartial and rational knowledge as the better reflection of reality (Tong, 2002). Hence, the two approaches are diametrically opposed, the "caring" approach stressing the "wants, needs and interests of other people" and the "rational" approach stressing the abstract concepts of justice, fairness and equality (Tong, 1998, p. 158).

But using an "ethic of caring" to underpin a requirement for empathy in the patient-physician relationship would be problematic. Firstly, by valuing interdependence and attachment over autonomy, it would allow that one or other member of the relationship can be subject to the caring (or empathic) demands of the other when it is not in their best interests or wishes to do so. Similarly, the ending of a relationship "may be necessary to one's physical or psychological well-being to do so but...it can never be caring, which... means that it can never be moral" (Clement, 1996, p. 37). This has important implications for the patient- physician relationship. Not all patients wish to be the object of caring and empathy; patients are often embarrassed enough by "the invasive intrusion of privacy" often necessary in medicine, and do not welcome personal questions about their emotional state, concerns, beliefs or values (Stockdale \& Warelow, 2000, p. 1262). Furthermore, the violation of professional boundaries by the patient (verbal or physical abuse, personal questions, overt affection, expensive gifts) could not, on this view, be used as a basis for terminating the patient-physician relationship without that act of termination being understood as lacking in morality (which is certainly counterintuitive). Thus, a major danger of valuing caring or empathy more than patient and physician autonomy is that it makes both parties - the "one-caring" and the "cared-for" - vulnerable to exploitation.

Secondly, an ethic of caring holds that our moral obligations and behaviour "arise out of our natural impulses to care": ethical caring requires natural caring (Noddings, 1984, p. 51). But whether or not we care (or empathize) for a particular patient is not entirely up to us; we may happen to "naturally" care for someone or we may not. It is difficult to effect genuine feelings of care and empathy if they are not spontaneously experienced. Should the moral worth of our actions be determined by such natural contingencies? This would mean that no caring relationship is intrinsically valuable; the value of relationships would instead be contingent upon the participants' natural impulses to care.

Thirdly, according to an ethic of caring, our moral obligations are given to us by the nature of our relationships and thus recognized rather than chosen: these obligations arise directly from our caring feelings towards certain people. By consequence, the more one cares for a person, the greater the moral obligations towards them. But as Hume rightly noted, it is part of our psychological constitution that we tend towards partiality, identifying with those who are more like us over those who are different. Hence, by appealing to caring and connectedness as the criteria for the moral worth of actions, a physician could justify favouring some patients (those whom he likes or identifies with) over others, as in allocating more time and attention to his affable patients than to his depressed or cantankerous ones. He should also be under no moral obligation to help those dying of AIDS in Africa, since he has no direct caring relationship with them ("real caring requires actual encounters with specific individuals" [Tong, 1993, p. 110]). It would actually be immoral for a family physician to leave his own patients (and hire an unfamiliar locum as a replacement) in order to do a 3-month stint with Médécins sans Frontières; he would be shirking his moral responsibilities to his patients in favour of others whom he has no moral obligation to help. These are consequences of the low priority of justice and equality in an ethic of caring. Indeed, equality of treatment (of patients with similar needs) is actually immoral on this view, since the physician is morally obligated to treat those patients he cares for differently than those he does not care for. Patients have no rights to fair and equal treatment within an ethic of caring (nor any other robust rights, for that matter), since the concept of rights is defended by the "male-oriented," justicebased theories that conceive of equality as more valuable than partiality. 
Based on these reasons alone, I think it is fair to conclude that an ethic of caring should not be made the theoretical basis for defining "good" physician conduct as necessarily empathic.

\section{Should Empathy be Considered A Necessary Virtue of "Good" Physicians?}

Perhaps empathy is "good" because it is a trait of virtuous people, and virtuous people are "good"? Virtue ethics, first elaborated by Aristotle in his Nicomachean Ethics, may seem uniquely well-suited as a theoretical framework for an ethic of empathy: it is centrally concerned with matters of character and particularism ("the belief that specific rules cannot be applied to all, or perhaps any, ethical problems"), and allows a role for emotions in ethical decision-making (Allmark, 1998, p. 467). According to Aristotle, every natural thing, including humans, has an end (a telos) which is unconditionally good for any member of that species. In Aristotelian philosophy, the human end is eudaimonia - to live a good, happy, flourishing life. The function of human beings is determined by that end: insofar as all human beings are unique in being able to reason, our function is to use reason to choose the means to eudaimonia. What does this have to do with virtue? Human virtues are just the qualities that allow us to fulfill this unique human function well: hence, the purpose of Aristotle's virtue ethics was not merely to provide a guide for making "good" choices, but also "to identify the best, most satisfying life for someone to lead" (Allmark, 1998, p. 468).

Aristotle listed the virtues that he saw as necessary for eudaimonia; empathy was not among them, but courage, temperance, patience/good temper, friendliness, modesty, truthfulness, and magnanimity were - and as amusing as it sounds today, so were wittiness, magnificence and religious indignation. Aristotelian virtues were all characterized as means between two extremes, and these extremes were termed "vices." For instance, wittiness is the stable disposition to be witty for the right reasons, to the right degree, and at the right time and place. The vice of "buffoonery" is manifest when someone has too much wit, leading them to be witty in the wrong way or at the wrong time and place; manifesting too little wit, by contrast, is the vice of "boorishness." These virtues are "stable states of character" that allow an individual to choose right consistently, and "choosing right" means choosing the right goals (which depends centrally upon one's values) for the right reasons (with the right motivation). In other words, the virtuous person cares about the right things in the right way, and has "settled tendencies to act and feel rightly" about them (Allmark, 1989, p. 469).

Can empathy, then, plausibly be conceived as a virtue of medical professionals? To do so, one first needs to determine the end (the goal or telos) of medicine as a professional endeavour. What is medicine for? That is, what is the unconditional good towards which all medical professionals should strive? The Royal College of Physicians of London describes medicine as primarily aimed at "protecting and restoring human well-being" (RCPL, 2005, p. 14). Other professional associations might characterize it differently, but no matter how precisely the words describing the telos of medicine are chosen, it is unlikely that every physician will agree on their meaning and implications for ethical conduct. This high- lights a potential problem with professional ethics in general. Insofar as professional values "encompass those values agreed upon by the profession as a whole," they must be characterized such that a majority of physicians will agree on them (Peppin, 1996, p. 294). The same could be said for the general moral principles by which physicians are expected to conduct themselves (justice, beneficence, non-maleficence, respect for autonomy). As an ethical framework for professional conduct that must be agreed upon by most members of the profession, it is difficult to make it substantive (in accordance with a specific conception of the "good" physician) without ignoring the right of individual physicians to have their own "non-negotiable notions of 'the good life", Peppin, 1996, p. 293).

Traditionally, the view was that physicians' personal values should be kept entirely out of the patient-physician relationship, but professional values are perfectly allowed to inform the physician's conduct with patients - indeed, they are supposed to. The justification for "value-neutrality" within the patient-physician relationship was that the physician's imposition of his personal values on patients would threaten the patient's autonomy (Peppin, 1996, p. 292). It is not entirely clear why the professional values of empathy, compassion and care are exempt from this argument, but the more important point is that it is simply fallacious to believe that physicians can avoid the encroachment of personal values into the patient-physician relationship. As Peppin (1996) notes, "any relationship between two persons involves values and these values are involved in the advice physicians give their patients":

[I]f patients with pneumonia refuse antibiotics, most physicians would attempt to manipulate the patients to change their decision. This would be based on a value system that believes taking the antibiotics is in a patient's best interest. A truly value-neutral physician would acquiesce to a patients' request without reflection or question (p. 292).

In this example, the physician interprets the basic moral principles of professionalism in such a way that the patient's well-being is more important than his autonomy. This is based on his personal value system which prioritizes beneficence over respect for autonomy (at least in this case). The profession may value patient autonomy more than patient well-being in this case, but does this mean the physician has behaved unethically? The profession would no doubt say "yes."

Ideally, a professional ethic is sufficiently nonsubstantive as to allow most individual physicians to agree upon it and then interpret it according to their own refined set of values and beliefs (which are otherwise consistent with the basic values of the profession). As noted in the Canadian Medical Association's Code of Ethics, "physicians may experience tension between different ethical principles, between ethical and legal or regulatory requirements, or between their own ethical convictions and the demands of other parties" (Preface, 2004). Thus, physicians are expected to use their unique "knowledge, skills and attitudes" deal with these conflicts. This ideal conception of the relationship between professional and personal ethics is based in part upon respect for physician autonomy. It is not reasonable to 
force a substantive ethical worldview onto physicians without their approval, nor is likely to work as a guide to their professional conduct. But this ideal is often abandoned nonetheless, in a seemingly arbitrary way. Consider the following example:

Any evidence of physical or sexual child abuse is to be reported to authorities. This is a legal requirement (and a correct one). However, to suggest that a woman who smokes, drinks, or uses illicit drugs is abusing her unborn child is considered, by many, a violation both of that woman's freedom and her "rights." Both positions involve very similar values, the protection of an innocent, yet one is considered proper for physicians and the other is considered an encroachment of personal values into the patientphysician relationship (Peppin, 1996, p. 295).

In this case as well, the physician's personal value system is deemed "inappropriate" as a guide to professional conduct. But the refusal by some physicians to perform abortions is considered perfectly acceptable. Why are the personal values that motivate this decision deemed appropriate, while those in the other cases are not? These cases involve conflicts between the profession's and the physician's interpretations of the "middle" principles of non-maleficence, beneficence and autonomy. In other words, the profession is interpreting its basic principles and values in a particular way, weighing its values and principles in order to resolve specific ethical dilemmas. This diverges from the ideal, however: it forces a substantive conception of ethics onto all medical professionals, preventing its framework principles and values from being adaptable to the unique ethical worldviews of individual physicians.

These issues pertain directly to our earlier question about how to characterize the telos of medicine (i.e., "the protection and restoration of human well-being") in terms that are acceptable to a majority of physicians. The meaning of this telos would be subject to substantial interpretation by individual physicians - indeed, it should be if the profession is to respect the right of physicians to have their own way of theorizing about ethical matters. By consequence, this leaves open the question of whether individual physicians must be empathic to be "good." Physicians will use their personal value systems and beliefs to choose the appropriate means for achieving this telos - that is, they will decide for themselves how they ought to be virtuous (constrained, of course, by the basic values and moral principles of the profession).

But should the profession override physician autonomy in the case of empathy? While most medical professionals may agree that empathy is valuable, a majority may not agree on making empathy a requisite virtue for the achievement of the telos of medicine. Some may argue that one can protect and restore the well-being of patients without empathizing with them; indeed, since it is impossible in practice to empathize with every patient, this is trivially true. But even in ideal circumstances, the personal qualities and beliefs of some physicians may entail that "doing the right thing" as a medical professional requires other traits such as integrity, excellence and respect for the patient -- but not empathy. For instance, some individuals may be less able to control their empathy and thus be overly prone to emotional attachments with patients, making them vulnerable to poor judgment, inefficiency, undue stress, and even burnout. For these physicians, empathizing is not conducive to the practice of "good" medicine. Other individuals may be Kantian in their ethical worldviews; they may be willing to recognize the value of empathy as a way of respecting human dignity and autonomy, but hold the moral law to be of paramount value. Moreover, the Kantian believes that moral decisions are those made by reason alone, unclouded by contingent emotions. By consequence, in situations in which empathy conflicts with their perceived capacity to act in accordance with the moral law, the moral law would always win. For these physicians as well, empathizing would not always be conducive to the practice of "good" medicine. Hence, in order for the medical profession to describe empathy as a requisite virtue for all physicians, it would have to override the right of physicians to have their own ethical worldviews and accept that those who are unwilling or unable to be genuinely empathic towards patients are by definition behaving unethically.

It is worth asking as well if empathy is even intelligible as a singular virtue. Based on my earlier description of genuine physician empathy, it seems to be, in actuality, inseparable from other traits and dispositions - namely, other virtues. Recall that for empathy to be "good" as a virtue, it must be manifested in the right way (directed at the appropriate people at the right time and place) and with the right motivation. Thus, the virtuous physician would need more than just the capacity for perspective-taking and cognitive and emotional insight into the patient's experience. He would need to have virtues of self-control: he must regulate his thoughts such that he focuses only on the patient, and he must regulate his emotions so that they are appropriately empathic. As a result, he manifests virtues of proper affect (emotional resonance with the patient as well as openness, caring and benevolent concern) and virtues of detachment (avoiding reactive emotions such as irritation or anger). He uses virtues of intuition to discern the patient's emotions and concerns using indirect verbal and nonverbal cues and virtues of intellect (ie. cognitive flexibility) to reflect upon them from their perspective rather than his own. He demonstrates virtues of patience, respect, curiosity and attentiveness during the patient interview, as well as social virtues allowing him to gain the patient's trust, ask well-attuned questions, and respond to the patient appropriately (note: this characterization of virtues is not Aristotle's; rather, it is inspired by Roberts' analysis of virtues as they relate to emotions [Roberts, 1989, pp. 2934]). In essence, if physicians are to be empathic in order to be "good," they need to have more traits and dispositions than are traditionally subsumed within the term "empathy." This is because empathy per se is not "good"; for it to be "good" as a virtue, it must be both properly motivated and properly executed.

\section{Can Physicians Choose to be Empathic?}

In the last section, I outlined some reasons to question the plausibility of defining virtuous physicians as necessarily empathic. Ultimately, however, I think it all comes down to the matter of choice. As a requirement for the practice of "good" medicine, empathy must be reasonably able to do its job: medical ethics is supposed to provide a framework by which physicians can choose, justify and evaluate their ac- 
tions. Thus, the claim that empathy is a necessary virtue of physicians must be a reasonable addition to a guide by which physicians can, willingly and conscientiously, conduct their professional lives. Aristotle's virtue ethics has reason at its core: one can only strive to be "good" by choosing the right means to the right end for the right reasons. But the context of his theory was "the good life" per se. An ethic of professional life, in particular, should have reachable goals, otherwise morale is at risk: if one cannot be "good" no matter how much one strives for it, what is the point of even trying (Van Hooft, 1987)?

A crucial and as-yet unaddressed tenet of Aristotle's philosophy is that virtues are latent or "potentially present" qualities present in most (but not all) human beings: just as "most acorns have the potential to develop into oak trees," so do most human beings have the potential to develop into virtuous people (Allmark, 1998, p. 467). Latent within us is the "practical knowledge" (a kind of intuitive, nonpropositional awareness) of what is "good" (Allmark, 1998, p. 470). The question is, how is this "practical knowledge" to be taught? For our purposes, the question should properly be phrased as: can empathy be taught? To what degree is it dependent on being blessed by nature? Aristotle held that virtues can be learned from virtuous agents or role models. Again, given the centrality of reason in his ethics, this means choosing the right role models, the right qualities in them from which to learn, and the right circumstances in which to learn from them. Upon development of the appropriate virtues, it is again reason that governs one's capacity to be virtuous in the right way and with the right motivation.

But Aristotle, as much as he contributed greatly to science, obviously lacked the insights into character, emotion and the human mind since revealed to us by modern philosophy, sociology, psychology, genetics and neuroscience (this is, after all, the same man who said that women were "deformed men," created when male babies failed to reach their full development [Aristotle, 1963 reprint, 737a28]). A significant amount of research has been done in these fields on the origin and nature of empathy, and an appreciation of these insights is important in answering our initial question: should empathy be a moral requirement for the practice of "good" medicine? Ultimately, I think the appropriate standpoint for an ethic of medical professionalism is a naturalistic one (like that of Aristotle). That is, medical ethics "must somehow be based on an appreciation of human nature - on a sense of what a human being is or might be, and on what a human being might want to have or want to be" (Dennett, 1996, p. 468).

What are some of these scientific insights into the nature of empathy? In what follows, I give just a sampling of the research that suggests a role for nature in the determination of individual differences in empathic abilities. Behavioural geneticists, for instance, have shown that genetically identical twins are more alike in their empathic responses than fraternal twins (who share $50 \%$ of their genes). In fact, J. Philippe Rushton and colleagues found that "50\% of the variance in altruism, empathy, nurturance and aggression was due to the genes with $50 \%$ due to environmental factors" (Rushton, 2004, p. 2583). And little of that environmental variance in altruism and empathy amongst twins was found to be due to their "common, shared environment" (i.e. parents' occupations, family cultural practice, parents' childrearing style). Rather, the environmental variance was mostly attributable to genotype-environment interactions. These interactions include, for instance, "evocative" genotype-environment correlations (whereby individuals receive responses from others that are influenced by their genotypes, as in empathic children receiving reciprocal empathy from others) and "active" genotype-environment correlations (whereby individuals create or select environments "that best suit them," as in naturally empathic children choosing empathic friends with whom to associate). Further, through "passive" genotype-environment interactions, parents not only pass along genes favourable to traits such as empathy, but are also more likely to "reinforce, model, and otherwise provide environments that enhance them" (Rushton et al., 1986 , p. 1196). Genes also account for $42 \%$ of the reliable variance in "pro-social behaviours" (i.e. feelings of social responsibility) (Rushton, 2004, p. 2585), an attribute that has been linked to empathy in other studies (Batson et al., 1997). Thus, evidence from behavioural genetics supports the view that individual differences in empathy are strongly influenced by genetic (and associated genotype-environment) influences (Plomin, 1990).

Gender differences in empathy have been welldocumented in the psychology literature: women consistently score higher on empathy ratings than men (this has also been shown to be true of female as compared to male physicians) (Hojat et al., 2002b, p. 1567; Hojat et al., 2002a; Eisenberg \& Lennon, 1983). The evolutionary theory of parental investment hypothesizes that this is due to women developing "more caregiving attitudes toward their offspring than men" (Trivers, 1972). Cambridge researcher Simon Baron-Cohen has proposed that the female brain is "hardwired" for empathizing: that is, on average, more females are wired to empathize (Baron-Cohen, 2003b). The malebrain, by contrast, is "hard-wired" for systematizing ("the drive to analyse and explore a system, to extract underlying rules that govern the behaviour of a system; and the drive to construct systems": on average, more males are wired to systematize rather than empathize (it is worth emphasizing that one's sex does not determine one's brain type: one can be female yet have a male-type brain). His theory certainly rings true at the anecdotal level; considering hobbies alone, men are more likely to engage in things like car or motorbike maintenance, sailing, bird-watching, or computer programming, while women are more likely to have phone conversations, care for pets, engage in coffee mornings or potluck suppers, or advise friends on relationship problems (BaronCohen, 2003a). Similar observations might be made about male- and female-dominated occupations or children's toy preferences.

The real evidence for Baron-Cohen's theory, however, comes from properly-designed studies that support the view that females demonstrate superior empathizing abilities as compared to males. For instance, women have been shown to be better at reading facial expressions, and at as early as age seven are better at judging when someone might have said something hurtful. Girls are less aggressive than boys during play, and baby girls as young as 12 months make more eye contact than boys and "respond more empathically 
to the distress of other people, showing greater concern through more sad looks, sympathetic vocalisations and comforting" (Baron-Cohen, 2003a). Indeed, shortly after birth, girls show a stronger preference to look at faces than mechanical mobiles, while the opposite is true of newborn boys. Males have been shown to be better at handling systems, as in reading maps, constructing $3 \mathrm{D}$ structures or mentally rotating shapes. In summary, Baron-Cohen does not deny a later role for culture and socialization in determining a male brain versus a female brain. He does, however, provide substantial evidence for a biological role in the determination of individual differences in empathizing and systematizing abilities.

Neurobiological research into empathy has yielded insight into the functional mechanisms that may underlie these gender differences, and may indeed explain (in part) the observed individual differences in the capacity to understand other people's intentions, feelings and actions. Empathy is fundamentally dependent upon "mind-reading" abilities, and until scientists began investigating the neural basis for empathy, the common belief was that we mainly gain insight into others' minds by using a specific "Theory of Mind" module (Baron-Cohen et al., 1985; Bouma, 2006). That is, we build "theories" about the minds of others using behaviour as evidence of their beliefs, desires, intentions and feelings. This involves either conscious or unconscious attributions of propositional contents (i.e. "He thinks I'm lying") to other individuals so that their behaviour "makes sense" to us and they are construed as rational agents.

Neurobiologists have now demonstrated that this explicit mind-reading strategy is secondary to a more primitive, largely unconscious one: mediated in part by "mirror neurons" in the premotor and parietal cortices, we have an innate neural mechanism for directly (automatically) "grasping the sense of the actions performed by others, and of the emotions and sensations they experience" (Gallese, 2006, p. 16). In 1995, researchers at the University of Parma, Italy discovered that when macaque monkeys observe other monkeys or humans execute a goal-related hand action (ie. grasping a nut), the same neural mechanisms are activated as when that monkey performs the action themselves (Rizzolatti et al., 1996). That is, the brain "lights up" in the same pattern whether the subject is performing a particular action or observing someone else performing that action. This finding has since been generalized to humans (though the involved brain regions are not entirely homologous to that of the monkey). Moreover, researchers have found that our brains are innately wired to "mirror" not only simple actions, but also intentions (Iacoboni et al., 2005; Fogassi et al., 2005), sensations (Ferrari et al., 2005; Watkins et al., 2003; Kohler et al., 2002), emotions (Goldman \& Sripada, 2005), and pain (Singer et al., 2004; Avenanti et al., 2005). And it is not a crude mirroring, either: when I watch you being touched on a specific part of your forearm, the somatosensory areas that encode sensation on my forearm are activated as well (Blakemore et al., 2005; Keysers et al., 2004). This has led some to describe the neural process of mirroring the experiences of others as "embodied simulation": "[s]ide by side with the sensory description of the observed social stimuli, internal representations of the body states associated with these actions, emotions, and sensations are evoked in the observer, "as if" he/she would be doing a similar action or experiencing a similar emotion or sensation" (Gallese, 2006, p. 20). This direct mechanism for experiencing empathy is obviously not the only way of understanding the minds of others, though it likely "scaffolds" our more sophisticated, conscious, cognitive strategies for empathizing (Gallese et al., 2004, p. 401).

The implications of this discovery for our understanding of empathy are obvious. Consider, for instance, our capacity to understand another person's emotions via this mechanism. When I taste something awful, my disgust is mediated by a specific pattern of activation in my brain (the anterior insula is the central locus); similarly, when I feel afraid, neurons in my amygdala discharge rapidly. But when I observe someone else with a disgusted or fearful facial expression (or just expressing these emotions in their voice [Johnstone et al., 2006]) the same pattern of activation occurs in my brain (particularly the anterior insula and amygdala, respectively) as when I myself am experiencing disgust (Wicker et al., 2003) or fear (Morris et al., 1996; Hamann et al., 2002). This "unmediated resonance" (Goldman \& Sripada, 2005) with the experience of another also occurs with pain: neurons in the anterior cingulate cortex and insula respond "not only when a person receives a painful stimulus but also when a person observes or anticipates a potentially painful stimulus" delivered to someone else (Singer et al., 2004, p. 1160). The sensory qualities of the other's pain are even mapped somatotopically onto the observers own sensory-motor system: a shock delivered to a particular muscle of the other person's hand also results in localized activation of the part of the observer's somatosensory cortex that encodes sensory stimulation of that part of the observer's hand. This mechanism of "embodied simulation" accounts for our empathic capacity to respond somatically and emotionally to the pain of others with corresponding feelings of anxiety, distress and anticipatory arousal: we subjectively feel the unpleasantness of their pain - without, thankfully, suffering the whole sensory experience of their pain (Singer \& Frith, 2005). Interestingly, this "embodied simulation" mechanism is also involved in imagination: when I imagine myself or another person in pain (or performing a certain action, or experiencing an emotion or sensation), roughly the same neural structures are activated as when I (or someone else) actually experience that pain (Singer et al., 2004; Decety \& Grèzes, 2006).

These neurobiologically-characterized mechanisms for empathy are not simply of passing interest to those working on the neural circuitry of the brain. They may indeed offer a different level of explanation, to complement studies done in psychology and genetics, for the variability in empathic capacities amongst individuals and groups. For instance, this "embodied simulation" mechanism, which mediates our "shared manifold" of experience with others, has been hypothesized as the basis for "intentional attunement" -- our intuitive capacity to decode the meaning of social stimuli (Gallese, 2005). Serious impairments in these intentional attunement capacities may explain, for instance, the deficits in social cognition characteristic of autism (at least better than previous theories) (Gallese, 2006). Further, differences in intentional attunement capacities (measurable through evidence of "simulation" on fMRI) may, in part, explain observed differences in empathy amongst neurotypical indi- 
viduals. For instance, one study has shown that individuals who score higher on self-rated as well as general empathy scales (i.e., the Balanced Emotional Empathy Scale and the Empathic Concern Scale) show stronger activations on fMRI in areas such as the anterior cingulate cortex (normally involved in the "mirroring" of another's pain) than those who scored lower on the same empathy scales (Singer et al., 2004, p. 1159). This area of the brain encodes our affective response to pain; hence, the high scorers felt more distressed on observing another person in pain than the low scorers.

Moreover, variations in the regulation of these simulation responses are important to understanding empathy differences amongst individuals. Studies have shown that there are consistent individual differences in "emotion regulation styles," though the relative contributions of nature and nurture to an individual's style are yet to be determined (Gross, 2002 , p. 288). Hence, individual differences in "embodied simulation" combined with differences in cognitive regulation styles each contribute to the particular way in which particular individuals express or experience empathy. For instance, people exhibit varying capacities to "reappraise" aversive emotional events (i.e. a physician's perception of a patient's painful cries) in "unemotional terms." This is a crucial activity of the prefrontal cortex, reducing negative affect "with few of the physiological, cognitive, or social costs associated with other emotional-regulatory strategies, such as the suppression of emotion-expressive behaviour" (Ochsner et al., 2002, p. 1215; Gross, 2002, p. 289). Thus, though two physicians may have similar "mirroring" capacities when observing a patient in pain, one may be better at cognitively reappraising the situation (i.e. by reminding himself that "I've given him a painkiller, so he'll soon feel better") so that he avoids experiencing its subjective unpleasantness, while the other may have to rely only on suppressing the outward expression of his palpable distress. In the latter case, the physician continues to experience the autonomic and affective arousal elicited by his neural simulation of the patient's pain, while in the former, the physician successfully modulates these representations so that he neurally simulates less of the patient's discomfort.

Taken together, this research suggests a significant role for nature in the determination of individual capacities for empathy. Biology likely accounts for many of the early differences in empathic responses between female-brained babies and male-brained babies. Meanwhile, other evidence also points to biology as a major determinant of adults' brain types as either "female" or "male." Indeed, this research shows that genetic differences and genotype-environment interactions together account for much more than half of the variance in empathizing ability between individuals. More specifically, genes may "wire" the brains of some individuals to be better at "mirroring" the actions, emotions and sensations of others, and may contribute to the ease with which some individuals can cognitively reappraise emotional situations in unemotional terms (providing control over the more primitive empathic responses). Though it would not be fair to conclude that nature alone determines how well an individual empathizes, it is fair to conclude that an individual's ability or tendency to empathize is not entirely "up to them." Unlike "being honest" or "respecting people's autonomy," it cannot be simply willed or chosen. This makes empathy a poor candidate as a requisite virtue of "good" poor candidate as a requisite virtue of "good" physicians, since physicians cannot necessarily choose to be empathic even if they want to be.

\section{WHAT SHOULD WE DO ABOUT EMPATHY, THEN?}

So empathy cannot justifiably be required of physicians as part of their role as professionals. What are the implications of this statement? Firstly, it entails that one can be a "good" physician without being empathic. One can certainly value empathy while at the same time failing to manifest it; the 174 physicians in the aforementioned study were representative of this apparent contradiction (see Introduction) (Carmel \& Glick, p. 1258). I've argued here that, for some of these physicians, the reasons why they fail to manifest empathy likely have nothing to do with the arduous conditions under which they work, the incongruous "culture" of medicine or the lack of training in appropriate communication skills. Some of these physicians may have inherited genes that predispose them to being poor at empathizing, inhibiting their capacities for "embodied simulation" of the emotions, sensations and intentions of others and giving them a "male brain" primed for systematizing instead of empathizing. To select against these individuals during medical admissions on the basis of their poor "empathy quotient," as has been suggested by others (Kupfer et al., 1982; Striet-Forest, 1982), would not only be unjustifiably discriminatory, but would impoverish the profession as a whole (as well as decrease the number of male physicians). After all, relatively unempathic individuals make up a significant proportion of cardiovascular surgeons, radiologists, neurosurgeons, orthopaedic surgeons, anaesthesiologists and pathologists (Hojat et al., 2002b, p. 1566; Newton et al., 2000, p. 1215). Moreover, patients sometimes select physicians whose style matches their own (though in this day and age, it is relatively rare to have a choice to begin with); as a male-brained female, I feel most comfortable with physicians who are likeminded - that is, forthright, efficient and cerebral, concerned more with diagnosing and treating my disease than my personal life, feelings and concerns. As noted earlier, not all patients wish to be the object of empathy and caring, and feel embarrassed enough as it is by the invasion of privacy that comes with medical treatment. Disregarding patients' wishes to be treated by male-brained physicians is equivalent to disregarding their autonomy.

This point warrants further examination. My arguments suggest that it is perfectly reasonable for both physicians as individuals and the profession of medicine as a whole to recognize empathy as a fundamental professional value without defining professional conduct as necessarily empathic. This may seem, on the surface, to be inconsistent. But medical ethics does not solely consist of values; it embraces as well the moral principles of beneficence, non-maleficence, respect for autonomy and justice. These principles assume other values that may be of equal or lesser importance than empathy. Hence, empathy could be construed as valuable, in some circumstances, because it is part of being beneficent towards patients and respecting their autonomy; in other circumstances, empathizing with patients could be inconsistent with other values, such as justice, autonomy or human wellbeing (particularly that of the physician). As long as empathy is not understood as the supreme value of medical profes- 
sionalism, it may, depending on the context, be trumped by other values. It can only be necessary for ethical physician conduct (generally speaking) if it is always necessary. And, as I noted earlier, physicians as individuals can also recognize empathy as a fundamental value without actually being empathic in their treatment of patients. Physicians can, for instance, have the desire or intention to empathize because they recognize its value, but be prevented from doing so by the characteristics of the patient or his illness, the context of the clinical encounter, or the physician's natural deficiency in empathizing ability.

Secondly, my arguments serve as a warning against mischaracterizing empathy as something that all medical students should feel they must manifest (in order to be "good" physicians). Doing so may inhibit their tendencies to empathize on the basis of an internal motivation to empathize. That is, if students learn that they will be graded on empathy, they may feel obligated to feign it in order to succeed in their clinical rotations or examinations. Instead of empathizing because of genuine feelings of caring or concern for the patient, they may empathize because they're afraid of the consequences of not doing so. For the same reasons, empathic behaviour should never be used as a basis for salary raises or promotions amongst practicing physicians. Instrumentalizing empathy in this way would also have the concomitant effect of decreasing professional morale. Male-brained physicians would likely experience feelings of personal failure and despair at their female-brained colleagues' achievements, being incapable of achieving the ideal no matter how much they try.

Thirdly, my arguments have potential implications for the much-debated question of how best to educate empathic physicians. Empathy should not be a moral imperative for physicians, nor should medical students intuit that they are required or expected to "behave empathically" in their treatment of patients. This means that attempts to engender empathy amongst neophyte physicians should ideally be implicit rather than explicit. Some facets of empathy (but not all) are more amenable to pedagogy than others: the capacity for reflection upon the patient experience of illness and "patient-centred" interviewing techniques are certainly among them. But even these facets are, it must be recognized, significantly "coloured" by traits that vary among individuals and are largely not self-determined. The female-brained student has a natural tendency to emotionally resonate with others, attuning them to subtle clues as to the patient's true feelings; the student who is extroverted in social orientation may more easily gain the patient's trust; the student with a disposition toward cognitive flexibility may be best at seeing the world from the perspective of the patient's values, beliefs and desires. Despite natural constraints on individual capacities to learn empathy-related skills, engagement in the humanities (Shapiro et al., 2004; Stepien \& Baernstein, 2006) and training in patient-centred interviewing (Benbassat \& Baumal, 2004; Stepien \& Baernstein, 2006) are reportedly beneficial as means to promote the cognitive, affective and behavioural components of empathy amongst medical students.

Others have argued that medicine is inherently a "moral enterprise" and medical education "a process of moral encul- turation" (Hafferty \& Franks, 1994, p. 870). For instance, students have traditionally been socialized to value empathy within the formal curriculum, and subsequently learn, within the hidden curriculum, to perceive patients as "gomers," "geeks," and "dirtballs" (Shem, S., 1978; Mizrahi, 1986). This conflict between the values to which medical education is explicitly committed (empathy, compassion, altruism) and those to which it is implicitly committed (detachment, moral relativism) is well-recognized today (Coulehan \& Williams, 2001; Hafferty \& Franks, 1994). One proposal for overcoming this contradiction is to instil in faculty - both within the formal curriculum of preclerkship and the "hidden" curriculum of clerkship - a sense of their role as purveyors of value (Hafferty \& Franks, 1994, pp. 869-870). As appropriate role models for moral education, faculty can implicitly encourage students to value empathy. Instead of explicitly training students to behave empathically, students would observe their preceptors' empathic behaviour and generate an internal motivation to emulate them - some, of course, being better at this than others. This would be an effective means for encouraging empathy without instrumentalizing it or misconstruing it as morally obligatory for the practice of "good" medicine.

\section{IN CONCLUSION}

Empathy within the patient-physician relationship clearly has many benefits. But this does not necessarily make it "good" as in "ethically required." In order to understand it as such, empathy would have to be subsumed within a substantive ethical theory such as virtue ethics or an ethic of caring. More generally, it would have to be a fair moral standard by which to judge physicians' conduct; that is, physicians would have to be uniformly capable of choosing to be empathic. I have argued here that neither of these conditions can be met. In actuality, empathy stands alongside other professional values such as compassion, integrity, excellence, and dedication, which, in addition to the four "middle" principles (justice, respect for autonomy, beneficence, and nonmaleficence), form the framework of contemporary medical ethics. Given that empathy is not understood as the supreme value of professionalism, nor as required for acting in accordance with the four principles, it cannot be construed as necessary for ethical physician conduct. Hence, the malebrained physicians of the world need not despair: they can still be "good" without being empathic in their treatment of patients.

\section{ACKNOWLEDGEMENTS}

I would like to thank Memorial University's Faculty of Medicine for supporting this research in the form of a Summer Undergraduate Research Award (2007), and Dr. Jim Connor for giving me free rein as my supervisor.

\section{REFERENCES}

Allmark, P. (1998). Is caring a virtue? Journal of Advanced Nursing, 28, 466-472.

American Medical Association. (1992, May). Public Opinion on Health Care Issues.

Aristotle. (1963 reprint). Generation of Animals. Cambridge, MA: Harvard University Press.

Avenanti, A., Bueti, D., Galati, G., \& Aglioti, S.M. (2005). Transcranial magnetic stimulation highlights the sensorimotor side of empathy for pain. Nature Neuroscience, 8, 955-60. 
Bagshaw, M., \& Adams M. (1986). Nursing home nurses' attitudes, empathy, and ideologic orientation. International Journal of Aging and Human Development, 22, 235-246.

Baron-Cohen, S., Leslie, A.M., \& Frithm, U. (1985). Does the autistic child have a "theory of mind"? Cognition, 21, 37-46.

Baron-Cohen, S. (2003a, April 17). They just can't help it. The Guardian. Retrieved May 5, 2007 from the World Wide Web: http://education.guardian.co.uk/higher/research/story/0,,938022,00. $\underline{\mathrm{html}}$

Baron-Cohen, S. (2003b, July 1). The Essential Difference: The Truth about the Male and Female Brain. Perseus Books Group.

Batson, C.D., Polycarpou, M.P., Harmon-Jones, E., Imhoff, M.J., Mitchener, E.C., \& Bender, L.L. (1997). Empathy and attitudes: can feeling for a member of a stigmatized group improve feelings toward the group? Journal of Personality and Social Psychology, 72, 105118.

Beauchamp, T., \& Childress, J. (1994). Principles of Biomedical Ethics ( $^{\text {th }}$ ed). New York: Oxford University Press.

Benbassat, J., \& Baumal, R. (2004). What is empathy, and how can it be promoted during clinical clerkships? Academic Medicine, 79, 832839.

Blakemore, S.-J., Bristow, D., Bird, G., Frith, C., \& Ward, J. (2005). Somatosensory activations during the observation of touch and a case of vision-touch synaesthesia. Brain, 128, 1571-1583.

Blumgart, H. (1964). Caring for the patient. New England Journal of Medicine, 270, 449-456.

Bouma, H. (2006). Radical interpretation and high-functioning autistic speakers: a defense of Davidson on thought and language. Philosophical Psychology, 19, 639-662.

Brotheridge, C.M., \& Lee, R.T. (2002). Testing a conservation of resources model of the dynamics of emotional labor. Journal of Occupational Health Psychology, 7, 57-67.

Burack, J.H., Irby, D.M., Carline, J.D., Root, R.K., \& Larson, E.B. (1999). Teaching compassion and respect: Attending physicians' responses to problematic behaviors. Journal of General Internal Medicine, $14,49-55$

Butow, P., Maclean, M., Dunn, S., Tattersall, M., \& Boyer, M. (1997). The dynamics of change: cancer patients' preferences for information, involvement and support. Annals of Oncology, 8, 857-863.

Carmel, S., \& Glick, S.M. (1996). Compassionate-empathic physicians: personality traits and social-organizational factors that enhance or inhibit this behaviour pattern. Social Sciences of Medicine, 43, 1253-1261.

Clement, G. (1996). Care, Autonomy, and Justice: Feminism and the Ethic of Care. Boulder, Colorado: Westview Press.

Canadian Medical Association Code of Ethics. (2004). Retrieved on September 5, 2006 from the World Wide Web: http://www.cma.ca/index.cfm/ci_id/2419/la_id/1.htm

Coulehan, J., \& Williams, P.C. (2001). Vanquishing virtue: the impact of medical education. Academic Medecine, 76, 598-605.

Crain, W.C. (1985). Theories of Development (pp. 118-136). Prentice-Hall.

Curzer, H.J. (1993). Is care a virtue for health care professionals? Journal of Medicine and Philosophy, 18, 51-69.

Decety, J., \& Grèzes, J. (2006). The power of simulation: imagining one's own and other's behavior. Brain Research, 1079, 4-14.

Dennett, D. (1996). Darwin's Dangerous Idea: Evolution and the Meanings of Life. Simon \& Shuster.

Eisenberg, N., \& Lennon, R. (1983). Sex differences in empathy and related capacities. Psychology Bulletin, 94, 100-131.

Ferrari, P.F., Maiolini, C., Addessi, E., Fogassi, L., \& Visalberghim, E. (2005). The observation and hearing of eating actions activates motor programs related to eating in macaque monkeys. Behavioral Brain Research, 161, 95-101.

Fogassi, L., Ferrari, P.F., Gesierich, B., Rozzi, S., Chersi, F., \& Rizzolatti, G. (2005). Parietal lobe: From action organization to intention understanding. Science, 302, 662-667.

Fox, R., \& Lief, H. (1963). Training for "detached concern." In Lief, H (Ed.), The Psychological Basis of Medical Practice. New York, NY: Harper \& Row.

Gallese, V., Keysers, C., \& Rizzolatti, G. (2004). A unifying view of the basis of social cognition. Trends in Cognitive Sciences, 8, 396-403.

Gallese, V. (2005). Embodied simulation: from neurons to phenomenal experience. Phenomenology and the Cognitive Sciences, 4, 23-48.

Gallese, V. (2006). Intentional attunement: a neurophysiological perspective on social cognition. Brain Research, 1079, 15-24.
Gilligan, C. (1982). In a Different Voice. Cambridge, MA: Harvard University Press.

Goldman, A., \& Sripada, C.S. (2005). Simulationist Models of Face-based Emotion Recognition. Cognition, 94, 193-213.

Gross, J.J. (2002). Emotion regulation: affective, cognitive, and social consequences. Psychophysiology, 39, 281-291.

Gruen, R.J., Mendelsohn, G. (1986). Emotional responses to affective displays in others: the distinction between empathy and sympathy. Journal of Personality and Social Psychology, 51, 609-614.

Hafferty, F.W., Franks, R. (1994). The hidden curriculum, ethics teaching, and the structure of medical education. Academic Medicine, 69, 861-71.

Halpern, J. (2001). From Detached Concern to Empathy: Humanizing Medical Practice. New York, NY: Oxford University Press.

Halpern, J. (2003). What is clinical empathy? Journal of General Internal Medicine, 18, 670-674.

Hamann, S.B., Ely, T.D., Hoffman, J.M., \& Kilts, C.D. (2002). Ecstasy and agony: activation of the human amygdala in positive and negative emotion. Psychological Science, 13, 135-141.

Hojat, M., Gonnella, J.S., Mangione, S., Nasca, T.J., Veloski, J.J., Erdmann, J.D., Callahan, C.A., \& Magee, M. (2002a). Empathy in medical students as related to academic performance, clinical competence and gender. Medical Education, 36, 522-527.

Hojat, M., Gonnella, J., Nasca, T., Mangione, S., Vergare, M., \& Magee, M. (2002b). Physician empathy: definition, components, measurement, and relationship to gender and specialty. American Journal of Psychiatry, 159,1563-1569.

Hojat, M., Mangione, S., Nasca, T.J., Rattner, S., Erdmann, J.B., Gonnella, J.S., \& Magee, M. (2004). An empirical study of decline in empathy in medical school. Medical Education, 38, 934-41.

Iacoboni, M., Molnar-Szakacs, I., Gallese, V., Buccino, G., Mazziotta, J., \& Rizzolatti, G. (2005). Grasping the intentions of others with one's owns mirror neuron system. PLOS Biology, 3, 529-535.

Johnstone, T., van Reekum, C.M., Oakes, T.R., \& Davidson, R.J. (2006). The voice of emotion: an FMRI study of neural responses to angry and happy vocal expressions. Social Cognitive and Affective Neuroscience, 1, 242-249.

Keysers, C., Wickers, B., Gazzola, V., Anton, J-L., Fogassi L., \& Gallese V. (2004). A touching sight: SII/PV activation during the observation and experience of Touch. Neuron, 42, 1-20.

Kohler, E., Keysers, C., Umiltà, M.A., Fogassi, L., Gallese, V., Rizzolatti, G. (2002). Hearing sounds, understanding actions: Action representation in mirror neurons. Science, 297, 846-848.

Kupfer, D.J., Drew, F.L., Curtis, E.K., \& Rubinstein, D.N. (1978). Personality style and empathy in medical schools. Journal of Medical Education, 53, 507-9.

Larson, E.B., Yao, X. (2005). Clinical empathy as emotional labor in the patient-physician relationship. JAMA, 293, 1100-1106.

Levinson, W. (1994). Physician-patient communication: a key to malpractice prevention. JAMA, 273, 1619-1620.

Lu, M.C. (1995).Why it is hard for me to learn compassion as a third year medical student. Cambridge Quarterly of Health Care Ethics, 4, 454-458.

Mizrahi, T. (1986). Getting Rid of Patients: Contradictions in the Socialization of Physicians. New Brunswick, New Jersey: Rutgers University Press.

Morris, J.S., Frith, C.D., Perrett, D.I., Rowland, D., Young, A.W., Calder, A.J., \& Dolan, R.J. (1996). A differential neural response in the human amygdala to fearful and happy facial expression. Nature, $383,812-815$.

Newton, B.W., Savidge, M.A., Barber, L., Cleveland, E., Clardy, J., Beeman, G., \& Hart, T. (2000). Differences in medical students' empathy. Academic Medicine, 75, 1215 .

Nightingale, S.D., Yarnold, P.R., Greenberg, M.S. (1991). Sympathy, empathy, and physician resource utilization. Journal of General Internal Medicine, 6, 420-423.

Noddings, N. (1984). Caring: A Feminine Approach to Ethics \& Moral Education. Berkeley: University of California Press.

Ochsner, K.N., Bunge, S.A., Gross, J.J., \& Gabrieli, J.D.E. (2002). Rethinking feelings: an fMRI study of the cognitive regulation of emotion. Journal of Cognitive Neuroscience, 14, 1215-1229.

Osler, W. (1963). Aequanimitas. New York, NY: Norton.

Peppin, J.F. (1996). Physicians' values and physician-value neutrality. Journal of Religion and Health, 34, 287-299. 
Platt, F.W., \& Keller, V.F. (1994). Empathic communication: a teachable and learnable skill. Journal of General Internal Medicine, 9, 222226.

Plomin, R. (1990). The role of inheritance in behavior. Science, 248, 183188.

Restak, R. (2006). The Naked Brain: How the Emerging Neurosociety is Changing How We Live, Work, and Love. New York: Harmony Books.

Rietveld, S., \& Prins, P. (1998). The relationship between negative emotions and acute subjective and objective symptoms of childhood asthma. Psychology and Medicine, 28, 407-415.

Rizzolatti, G., Fadiga, L., Gallese, V., \& Fogassi, L. (1996) Premotor cortex and the recognition of motor actions. Cognitive Brain Research, 3, 131-141.

Roberts, R.C. (1989). Aristotle on virtues and emotions. Philosophical Studies, 56, 293-306.

Roter, D., Stewart, S., Putnam, N., Lipkin, M. (1997a). Communication patterns of primary care physicians. JAMA, 277, 350-6.

Roter, D., Hall, J., Merisca, R., Nordstrom, B., Cretin, D., \& Svarstad, B. (1997b). Effectiveness of interventions to improve patient compliance: a meta-analysis. Medical Care, 36, 1138-61.

Royal College of Physicians of London. (2005). Doctors in society: Medical professionalism in a changing world. Retrieved June 10, 2007 from the World Wide Web: http://www.rcplondon.ac.uk/pubs/books/docinsoc/docinsoc.pdf

Rushton, J.P., Fulker, D.W., Neale, M.C., Nias, D.K., \& Eysenck, H.J. (1986). Altruism and aggression: the heritability of individual differences. Journal of Personality and Social Psychology, 50, 11921198.

Rushton, J.P. (2004). Genetic and environmental contributions to pro-social attitudes: a twin study of social responsibility. Proceedings of the Royal Society of Britain B, 271, 2593-2585.

Shapiro, J., Morrison, E., Boker, J. (2004). Teaching empathy to first year medical students: evaluation of an elective literature and medicine course. Education for Health, 17, 73-84.

Shem S. (1978). The House of God. New York: Dell.

Singer, T., Seymour, B., O’Doherty, J., Kaube, H., Dolan, R.J., \& Frith, C.F. (2004). Empathy for pain involves the affective but not the sensory components of pain. Science, 303, 1157-1162.

Singer, T., \& Frith, C. (2005). The painful side of empathy. Nature Neuroscience, $8,845-846$.

Spencer, J. (2004). Decline in empathy in medical education: how can we stop the rot? Medical Education, 38, 916-920.
Stepien, K.A., \& Baernstein, A. (2006). Educating for empathy: a review. Journal of General Internal Medicine, 21, 524-530.

Stockdale, M., \& Warelow, P.J. (2000). Is the complexity of care a paradox? Journal of Advanced Nursing, 31, 1258-1264.

Striet-Forest, U. (1982). Differences in empathy: a preliminary analysis. Journal of Medical Education, 57, 65-7.

Suchman, L.A., Roter, D., Green, M., \& Lipkin, M. (1993). Physician satisfaction with primary care office visits: collaborative study group of the American Academy on Physician and Patient. Medical Care, 31, 1083-1092.

Thomas, M.R., Dyrbye, L.N., Huntington, J.L., Lawson, K.L., Novotny, P.J., Sloan, J.A., \& Shanafelt, T.D. (2007). How do distress and well-being relate to medical student empathy? A multicenter study. Society of General Internal Medicine, 22, 177-183.

Tong, R. (1993). Feminine and Feminist Ethics. Belmont, CA: Wadsworth Publishing Co.

Tong, R. (2002). Feminist ethics. The Stanford Encyclopedia of Philosophy. Zalta E.N. (Ed.) Retrieved June 3, 2007 from the World Wide Web: http://plato.stanford.edu/archives/fall2002/entries/feminismethics

Tong, R. (1998). Feminist Thought: A more Comprehensive Introduction. Boulder, Colorado: Westview Press.

Trivers, R.L. (1972). Parental investment and sexual selection. In Sexual Selection and the Descent of Man, pp. 136-179. Campbell, B. (Ed.). Chicago: Aldine.

Van Hooft, S. (1987). Caring and professional commitment. AustralianJournal of Advanced Nursing, 4, 29-38.

Watkins, K.E., Strafella, A.P., \& Paus, T. (2003). Seeing and hearing speech excites the motor system involved in speech production. Neuropsychologia, 41, 989-94.

Wicker, B., Keysers, C., Plailly, J., Royet, J-P., Gallese, V., \& Rizzolatti, G. (2003). Both of us disgusted in my insula: The common neural basis of seeing and feeling disgust. Neuron, 40, 655-664.

Winefield, H.R., \& Chur-Hansen, A. (2000). Evaluating the outcome of communication skill teaching for entry-level medical students: does knowledge of empathy increase? Medical Education, 34, 90-94.

Wispé, L. (1986). The distinction between sympathy and empathy: to call forth a concept, a word is needed. Journal of Personality and Social Psychology, 50, 314-321.

Wolf, E.S. (1980). The dutiful physician: the central role of empathy in psychoanalysis, psychotherapy, and medical practice. Clinical Psychiatry, 2, 41-56. 